\section{Fragile X population carrier screening}

To the editor: We read with interest Dr Grody's commentary, "Expanded Carrier Screening and the Law of Unintended Consequences: From Cystic Fibrosis to Fragile X," in which he makes the point that there is an increasing trend to include rare and low-penetrant mutations of unpredictable genotype-phenotype correlations in carrier screening, most notably in cystic fibrosis, which has led to adverse outcomes. $\mathrm{He}$ also notes that these have happened even in planned and piloted large public health programs, most likely as a result of changes from the original planning that subsequently occurred in practice, or due to the drive to go beyond the original scope, which can be based simply on increasing the market share. Dr Grody also comments on this tendency in carrier screening for other conditions such as fragile $\mathrm{X}$ syndrome. We agree with Dr Grody's sentiments and do think it is critical to plan, pilot-test, and evaluate carrier screening programs and then be assiduous in ensuring that ultimate practice is based on the findings. However, when he mentioned that carrier screening for fragile $\mathrm{X}$ syndrome is increasingly popular, he also stated that this is occurring "in the absence of any pilot studies or professional recommendations, and, to this author at least, illustrates the law of unintended consequences only too well."

In this journal in 2008, we published an article titled "A Model for Offering Carrier Screening for Fragile X Syndrome to Non-Pregnant Women: Results From a Pilot Study" in which uptake of testing, knowledge of fragile X syndrome, and attitudes to screening were measured. ${ }^{2}$ We outlined the careful process taken to develop the screening pilot program and we also explored in depth the experiences of women who were offered the fragile $\mathrm{X}$ carrier test through this pilot study. ${ }^{3}$ We found that participants were interested to learn more about screening, valued having time for deliberation, and did not appear to regret their decisions, either to be tested or not. We also subsequently published in this journal a systematic review of population carrier screening ${ }^{4}$ in which we emphasised some key challenges of population-based carrier screening for fragile $\mathrm{X}$ syndrome and related disorders (including those associated with the nature of predictive testing of FMR1) and made the recommendation that more research studies that go beyond solely measuring uptake of testing are critical. To this aim, we are currently undertaking a study that compares informed decision-making and other psychosocial factors in nonpregnant and pregnant women offered screening to inform the development of large-scale programs. Indeed, such studies are also a recommendation from the National Society of Genetic Counselors ${ }^{5}$ and the American College of Medical Genetics. ${ }^{6}$

Although the introduction of any new screening test should be carefully considered, some of the issues Dr Grody raises can be managed by the way in which screening is offered. If screening is offered prior to pregnancy, there are a greater range of reproductive options available to individuals who receive a carrier result. In addition, the test can be considered without the time pressure associated with screening during the prenatal period. This, as well as the development of evaluated educational materials tailored to the informational needs of the screening target population, may mean that individuals offered screening are able to fully consider the implications of screening, including the impact of learning information that may have implications for one's health, which is the case for FMR1 premutation carriers. Dr Grody's concerns are well-founded, and it is incumbent on researchers, policy makers, and service providers to be aware of findings and recommendations that exist in the scientific literature and spend time considering approaches to offering screening that minimize potential harms, so that unintended consequences of screening programs can be mitigated.

\section{DISCLOSURE}

The authors declare no conflict of interest.

Sylvia A. Metcalfe, PhD ${ }^{1,2}$ and Alison D. Archibald, Grad Dip Genet Couns, $P h D^{1,3}$

\footnotetext{
${ }^{1}$ Murdoch Childrens Research Institute, The Royal Children's Hospital, Parkville, Australia; ${ }^{2}$ Department of Paediatrics, The University of Melbourne, The Royal Children's Hospital, Parkville, Australia; ${ }^{3}$ Victorian Clinical Genetics Services, The Royal Children's Hospital, Parkville, Australia.

E-mail: sylvia.metcalfe@mcri.edu.au
}

\section{REFERENCES}

1. Grody WW. Expanded carrier screening and the law of unintended consequences: from cystic fibrosis to fragile X. Genet Med 2011;13: 996-997.

2. Metcalfe $S$, Jaques A, Archibald A, et al. A model for offering carrier screening for fragile $X$ syndrome to nonpregnant women: results from a pilot study. Genet Med 2008; 10:525-535.

3. Archibald A, Jaques A, Wake S, et al. "It's something I need to consider": women's decisions about population carrier screening for fragile $X$ syndrome. Am J Med Genet, Part A, 2009;149A:2731-2738.

4. Hill MK, Archibald AD, Cohen J, Metcalfe SA. A systematic review of population screening for fragile X syndrome. Genet Med 2010;12: 396-410.

5. McConkie-Rosell A, Finucane B, Cronister A, Abrams L, Bennett RL, Pettersen BJ. Genetic counseling for fragile x syndrome: updated recommendations of the national society of genetic counselors. J Genet Couns 2005;14: 249-270.

6. Sherman S, Pletcher BA, Driscoll DA. Fragile X syndrome: diagnostic and carrier testing. Genet Med 2005;7:584-587. 